\title{
Prediction of extubation failure in preterm infants
}

\section{G Dimitriou, A Greenough, A Endo, S Cherian, G F Rafferty}

Arch Dis Child Fetal Neonatal Ed 2002;86:F32-F35

See end of article for authors' affiliations

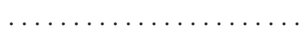

Correspondence to: Professor Greenough, Department of Child Health, King's College Hospital, London SE5 9RS, UK: anne.greenough@kcl.ac.uk

Accepted 23 August 2001

\begin{abstract}
Objective: To identify whether the results of assessment of respiratory muscle strength or respiratory load were better predictors of extubation failure in preterm infants than readily available clinical data. Patients: Thirty six infants, median gestational age 31 (range 25-36) weeks and postnatal age 3 (1-14) days; 13 were $<30$ weeks of gestational age.

Methods: Respiratory muscle strength was assessed by measurement of maximum inspiratory pressure generated during airway occlusion, and inspiratory load was assessed by measurement of compliance of the respiratory system.

Results: Overall, seven infants failed extubation - that is, they required reintubation within 48 hours. These infants were older $(p<0.01)$, had a lower gestational age $(p<0.01)$, and generated lower maximum inspiratory pressure $(p<0.05)$ than the rest of the cohort. Similar results were found in the infants $<30$ weeks of gestational age. Overall and in those $<30$ weeks of gestational age, gestational age and postnatal age had the largest areas under the receiver operator characteristic curves.

Conclusion: In very premature infants, low gestational age and older postnatal age are better predictors of extubation failure than assessment of respiratory muscle strength or respiratory load.
\end{abstract}

$\mathrm{P}$ rolonged ventilatory support increases the risk of complications, such as nosocomial infection, ${ }^{1}$ emphasising the importance of extubating infants as soon as possible. Yet, about one third of premature infants fail extubation-that is, they subsequently require extra respiratory support in the form of continuous positive airways pressure (CPAP) or reventilation. ${ }^{2}$ These data indicate that currently used criteria to indicate readiness to wean and extubate are relatively inaccurate. We have shown that a low lung volume ${ }^{3}$ and small chest radiograph lung area ${ }^{4}$ after extubation could predict extubation failure. Although a low lung volume performed better than a low compliance of the respiratory system (CRS) and commonly used clinical indices, it performed less well than a low gestational age. ${ }^{5}$ In addition, a low lung volume or small lung area after extubation has limited usefulness, as the infant has already been extubated. Ideally, infants likely to fail extubation should be identified before removal of the endotracheal tube and that manoeuvre delayed to a more appropriate time. Infants who have a low lung volume after extubation may have an unfavourable balance between respiratory muscle strength and respiratory load. Our aim was to test the hypothesis that infants who failed extubation, particularly those born very immaturely-that is, at less than 30 weeks of gestational age-have reduced respiratory muscle strength rather than a high respiratory load.

\section{METHODS}

Premature infants less than or equal to 2 weeks of age receiving mechanical ventilation were studied if they were deemed by the clinician in charge ready to be extubated. All were ventilated through oral shouldered endotracheal tubes using time cycled pressure limited ventilators (SLE 2000; SLE Ltd, Croydon, Surrey, UK). All infants followed the routine weaning policy. At a ventilator rate of 40 breaths/minute, infants were started on caffeine (a loading dose of $20 \mathrm{mg} / \mathrm{kg}$ and then maintenance of $5 \mathrm{mg} / \mathrm{kg} / 24$ hours) and changed to patient triggered ventilation. The inspiratory time $(0.3-0.4$ seconds) remained constant throughout the weaning process. The peak inspiratory pressure was reduced as blood gas results permitted. At least 12 hours before extubation, all sedation was stopped and caffeine administered. Infants were considered ready to be extubated once their peak pressure was $\leqslant 16 \mathrm{~cm}$ $\mathrm{H}_{2} \mathrm{O}$ and inspired oxygen concentration was $\leqslant 40 \%$. The decision to extubate was made by the clinical team who were unaware of the results of the respiratory muscle strength and respiratory function tests. The infant was then transferred to endotracheal CPAP for one hour. If a respiratory acidosis $\left(\mathrm{pH}<7.25\right.$ with a raised $\mathrm{PaCO}_{2}$ and base excess $\left.\leqslant 5\right)$ did not develop, the infant was extubated into a headbox containing an appropriate concentration of humidified oxygen to maintain a satisfactory arterial oxygen saturation. After extubation, blood gases were checked at least four hourly, but more frequently if indicated by changes in the continuous respiratory, heart rate, and oxygen saturation monitoring. Nasal prong CPAP was instituted by the clinical team according to routine policy - that is, if a respiratory acidosis or recurrent minor apnoeas developed. Infants were reintubated if they had a major apnoea, developed a severe respiratory acidosis ( $\mathrm{pH}<7.20$ ), or failed to improve despite the institution of CPAP.

Respiratory measurements were made once the clinician in charge deemed the infant ready to be extubated, informed written parental consent had been obtained, and within six hours before extubation. A pneumotachograph (Mercury FlL; GM Instruments, Kilwinning, Scotland) was inserted between the endotracheal tube and ventilator circuit. The pneumotachograph was attached to a differential pressure transducer (MP45; range $\pm 2 \mathrm{~cm} \mathrm{H}_{2} \mathrm{O}$; Validyne Corporation, Northridge, California, USA). The flow signal from the pneumotachograph was integrated to give volume (Gould Integrator model 13-4615-70; Cleveland, Ohio, USA). Airway pressure changes were measured from a side port on the pneumotachograph using a differential pressure transducer (MP45; range \pm 100 $\mathrm{cm} \mathrm{H}_{2} \mathrm{O}$; Validyne Corporation). Flow, volume, and pressure

Abbreviations: CPAP, continuous positive airways pressure; $\mathrm{CRS}$, compliance of the respiratory system; IP, inspiratory pressure; MIP, maximum inspiratory pressure; $\mathrm{PIP}$, peak inspiratory pressure; $\mathrm{FIO}_{2}$ inspired oxygen concentration; ROC, receiver operator characteristic. 
Table 1 Comparison of infants who did and did not fail extubation

\begin{tabular}{|c|c|c|c|}
\hline & Failure $(n=7)$ & Success $(n=29)$ & $p$ Value \\
\hline Gestational age (weeks) & $27(25-31)$ & $32(27-36)$ & $<0.01$ \\
\hline Birth weight $(\mathrm{g})$ & 918 (685-1752) & 1874 (938-2856) & $<0.01$ \\
\hline Postnatal age (days) & $8(2-14)$ & $2(1-9)$ & $<0.01$ \\
\hline Max PIP $\left(\mathrm{cm} \mathrm{H}_{2} \mathrm{O}\right)$ & $22(18-23)$ & $20(15-27)$ & NS \\
\hline $\mathrm{Max} \mathrm{FlO}_{2}$ & $0.65(0.31-0.78)$ & $0.44(0.21-0.94)$ & NS \\
\hline PIP before extubation & $12(11-15)$ & $12(10-16)$ & NS \\
\hline $\mathrm{FlO}_{2}$ before extubation & $0.30(0.22-0.38)$ & $0.23(0.21-0.36)$ & $<0.05$ \\
\hline $\mathrm{CRS}\left(\mathrm{ml} / \mathrm{cm} \mathrm{H}{ }_{2} \mathrm{O} / \mathrm{kg}\right)$ & $0.79(0.43-1.16)$ & 0.77 (0.32-2.18) & NS \\
\hline \multicolumn{4}{|l|}{ Inspiratory pressures } \\
\hline Mean IP $\left(\mathrm{cm} \mathrm{H}_{2} \mathrm{O}\right)$ & 11.3 (7.3-19.7) & $16.7(6.6-57.2)$ & $<0.03$ \\
\hline $\operatorname{Max} I P\left(\mathrm{~cm} \mathrm{H}_{2} \mathrm{O}\right)$ & 15.7 (12.7-25.1) & $23.3(9.2-77.0)$ & NS \\
\hline Max MIP $\left(\mathrm{cm} \mathrm{H}_{2} \mathrm{O}\right)$ & $17.3(12.7-30)$ & 32.7 (20.0-77.0) & $<0.01$ \\
\hline Mean MIP $\left(\mathrm{cm} \mathrm{H}_{2} \mathrm{O}\right)$ & $14.3(9.9-21.2)$ & $24.8(14.1-69.3)$ & $<0.01$ \\
\hline
\end{tabular}

signals were simultaneously recorded on a polygraph (Gould 2800S). During a brief period of disconnection from the ventilator, inspiratory pressures during an occlusion and CRS were measured. To measure inspiratory pressures, occlusions were made at end expiration and maintained through at least four respiratory cycles. At least three separate occlusions were made. The following inspiratory pressures were then determined:

(1) inspiratory pressure (IP): the inspiratory pressure generated by the first breath after the occlusion;

(2) mean IP: the mean IP from the series of occlusions;

(3) max IP: the maximum IP generated during the series of occlusions;

(4) maximum inspiratory pressure (MIP): the maximum inspiratory pressure generated during each occlusion:

(5) mean MIP: the mean of the MIPs from the series of occlusions;

(6) maximum MIP (max MIP): the maximum MIP generated during the series of occlusions.

Inspiratory pressures were also related to birth weight-that is, an infant's inspiratory pressures were divided by his/her birth weight.

CRS was measured using the occlusion technique. The occlusion was performed at end inspiration which provoked the Hering-Breuer reflex and hence a temporary apnoea, indicated by a positive pressure plateau of at least 0.3 second. ${ }^{6}$ CRS was calculated from the inspiratory volume immediately before the occlusion divided by the height of the airway pressure plateau during the occlusion. The mean of the results from 10 occlusions was calculated, and CRS then related to body weight. The coefficient of repeatability of CRS is 0.08 $\mathrm{ml} / \mathrm{cm} \mathrm{H}_{2} \mathrm{O}$.

The nursing staff recorded hourly on observation charts the infant's ventilator settings. From these charts, the infant's maximum peak inspiratory pressure (PIP) and inspired oxygen concentration $\left(\mathrm{FIO}_{2}\right)$ during ventilatory support and the PIP and $\mathrm{FIO}_{2}$ immediately before extubation were noted. The infant's gestational age, birth weight, and postnatal age were recorded.

\section{Analysis}

Extubation failure was diagnosed if an infant required reintubation within 48 hours of extubation. Differences between infants in whom extubation failed or succeeded were assessed for statistical significance using the Mann-Whitney U test. Receiver operator characteristic (ROC) curves were constructed, ${ }^{8}$ and the area under each ROC curve calculated ${ }^{9}$ and compared to determine which predictor performed best. Analysis was undertaken for the whole group and then for only those less than 30 weeks of gestational age.

\section{Patients}

Thirty six infants, median gestational age 31 weeks (range 25-36), birth weight $1569 \mathrm{~g}(685-2856)$, and postnatal age 3 days (1-14) were studied (table 1). Thirteen infants were less than 30 weeks of gestational age at birth (table 2). Their median gestational age was 28 weeks (range 25-99), birth

Table 2 Comparison of infants $<30$ weeks gestational age who did and did not fail extubation

\begin{tabular}{|c|c|c|c|}
\hline & Failure $(n=6)$ & Success $(n=7)$ & $\mathrm{p}$ Value \\
\hline Gestational age (weeks) & $27(25-28)$ & $29(27-29)$ & $<0.01$ \\
\hline Birth weight (g) & $899(685-1606)$ & 1170 (938-1440) & NS \\
\hline Postnatal age (days) & $9.5(5-14)$ & $2(2-7)$ & $<0.01$ \\
\hline $\operatorname{Max} \mathrm{PIP}\left(\mathrm{cm} \mathrm{H} \mathrm{H}_{2} \mathrm{O}\right)$ & $22(18-23)$ & $19(17-20)$ & $<0.03$ \\
\hline $\mathrm{Max} \mathrm{FiO}_{2}$ & $0.56(0.31-0.65)$ & $0.40(0.28-0.84)$ & NS \\
\hline PIP before extubation & $12.5(11-15)$ & $12(11-13)$ & NS \\
\hline $\mathrm{FlO}_{2}$ before extubation & $0.30(0.22-0.38)$ & $0.22(0.21-0.36)$ & NS \\
\hline $\mathrm{CRS}\left(\mathrm{ml} / \mathrm{cm} \mathrm{H} \mathrm{H}_{2} \mathrm{O} / \mathrm{kg}\right)$ & $0.80(0.47-1.16)$ & $0.77(0.50-1.02)$ & NS \\
\hline \multicolumn{4}{|l|}{ Inspiratory pressures } \\
\hline Mean IP $\left(\mathrm{cm} \mathrm{H}_{2} \mathrm{O}\right)$ & 11.7 (7.3-19.7) & $16.4(12-24.6)$ & $<0.04$ \\
\hline $\operatorname{Max} I P\left(\mathrm{~cm} \mathrm{H}_{2} \mathrm{O}\right)$ & 18.3 (12.7-25.1) & 21.3 (13.3-37.0) & NS \\
\hline $\operatorname{Max} M I P\left(\mathrm{~cm} \mathrm{H}_{2} \mathrm{O}\right)$ & 23.2 (12.7-30.0) & $32.7(21.3-62.6)$ & $<0.05$ \\
\hline Mean MIP $\left(\mathrm{cm} \mathrm{H}_{2} \mathrm{O}\right)$ & $15.6(9.9-21.2)$ & $25.2(18.0-45.7)$ & $<0.01$ \\
\hline
\end{tabular}

Data are median (range)

CRS, compliance of the respiratory system; IP, inspiratory pressure; MIP, maximum inspiratory pressure; PIP, peak inspiratory pressure; $\mathrm{FIO}_{2}$, inspired oxygen concentration. 
Table 3 Comparison of areas under the receiver operator characteristic curves

\begin{tabular}{lll}
\hline & All infants & $\begin{array}{l}\text { Infants }<30 \text { weeks } \\
\text { gestational age }\end{array}$ \\
\hline Gestational age & 0.93 & 0.93 \\
Birth weight & 0.86 & 0.81 \\
Postnatal age & 0.89 & 0.98 \\
Max PIP & 0.71 & 0.86 \\
Max FiO & 0.62 & 0.66 \\
CRS/kg & 0.54 & 0.51 \\
Inspiratory pressures & & \\
Mean IP & 0.78 & 0.86 \\
Max IP & 0.72 & 0.67 \\
Mean MIP & 0.90 & 0.95 \\
Max MIP & 0.82 & 0.83 \\
Inspiratory pressures corrected for birth weight \\
Mean IP $/ \mathrm{kg}$ & 0.59 & 0.69 \\
Max IP $/ \mathrm{kg}$ & 0.61 & 0.52 \\
Max MIP/kg & 0.53 & 0.62 \\
Mean MIP/kg & 0.52 & 0.81 \\
\hline
\end{tabular}

CRS, compliance of the respiratory system; IP, inspiratory pressure MIP, maximum inspiratory pressure; PIP, peak inspiratory pressure $\mathrm{FIO}_{2}$, inspired oxygen concentration.

weight 1018 g (range 685-1606), and postnatal age 5 days (2-14). The study was approved by the research ethics committee of King's Healthcare National Health Service Trust.

\section{RESULTS}

Seven infants failed extubation. Four infants were reintubated because of frequent apnoeas and bradycardias, two because of a severe apnoea, and the seventh because of a respiratory acidosis because of poor respiratory effort (this infant was 31 weeks of gestational age). The infants who failed extubation differed significantly from the rest of the cohort in having a lower gestational age $(p<0.01)$ and birth weight $(p<0.01)$ and requiring a higher $\mathrm{FiO}_{2}$ before extubation. In addition, those who failed extubation generated lower inspiratory pressures (table 1). The results, however, failed to reach statistical significance when the inspiratory pressures were corrected for birth weight. Considering only those infants who were less than 30 weeks of gestational age, those who failed extubation were significantly more immature $(p<0.01)$, of greater postnatal age $(p<0.01)$, and had required a higher maximum PIP $(p<0.03)$. In addition, the mean IP $(p<0.04)$, maximum IP $(p<0.05)$, and mean MIP $(p<0.01)$ were significantly lower in those who failed extubation (table 2). Similarly, in this subgroup the inspiratory pressures corrected for birth weight did not differ significantly between infants who failed or had a successful extubation. Comparison of the areas under the ROC curves showed the best predictors of extubation failure in the group overall and in those less than 30 weeks of gestational age were low gestational age and older postnatal age (table 3 ). Both a low gestational age and older postnatal age had high sensitivities and specificities in predicting extubation failure, particularly in those less than 30 weeks of gestational age (100\%, 86\% low gestational age; $83 \%, 100 \%$ older postnatal age).

\section{DISCUSSION}

We have shown that low gestational age and older postnatal age at attempted extubation were the most accurate predictors of extubation failure. The infants who failed extubation had more severe respiratory failure, as evidenced by their higher maximum PIP and inspired oxygen concentrations. Not surprisingly then, it took longer for their ventilator settings to be reduced to those at which weaning was routinely started and they required ventilator support for longer. It is possible that low respiratory muscle strength contributes to extubation failure in very immature infants and in those in whom extubation is attempted at an older age. Inspiratory muscle strength is related to maturity at birth, MIP being higher in term than preterm infants. ${ }^{10}$ Prolonged ventilation may result in impaired respiratory muscle strength, as disuse atrophy starts after only a few days of mechanical ventilation. ${ }^{11}$

To assess respiratory muscle strength, we measured the inspiratory pressure generated against an occlusion. Two occlusion methods can be used to obtain such data: one involves total airway occlusion at end exhalation and the second involves the use of a unidirectional expiratory valve to selectively permit exhalation while inspiration is blocked. ${ }^{12}$ Marini et $^{12}$ showed that the timing of the maximum pressure generated was not affected by the choice of methods, but the maximal pressure achieved using an expiratory valve almost invariably exceeded that obtained using the first method. MIP varies with the intensity of the respiratory drive, the duration of the manoeuvre, and the lung volume at the time of airway occlusion. ${ }^{13}{ }^{14}$ The likely explanation for the findings of Marini et al is that use of a unidirectional expiratory valve resulted in lower lung volumes and hence improved characteristics of the inspiratory muscles ${ }^{15}$ and enhanced ventilatory drive. At low lung volumes, inspiratory muscles are optimally lengthened and the geometry of the diaphragm is optimised. ${ }^{12}{ }^{15}$ Outward recoil of the relaxing chest wall also assists the inspiratory musculature in achieving inspiratory force near residual volume. ${ }^{16}$ Nevertheless, in this study, we used a method involving total airway occlusion and still saw significant differences between the infants who did and did not fail extubation.

Inspiratory load, as assessed by measurement of CRS before extubation, did not differ significantly between infants who did and did not fail extubation, confirming our previous findings. ${ }^{5}$ Our results therefore suggest that respiratory muscle strength is a more important contributor to extubation failure than high inspiratory load. Methlyxanthines improve diaphragmatic contractility ${ }^{17}$; all the infants included in this study were receiving caffeine when examined. Other strategies that may improve respiratory muscle strength in immature infants and hopefully decrease extubation failure are desirable.

Differences in the inspiratory pressures between infants who did or did not fail extubation were no longer significant when corrected for birth weight, the explanation being that it was the smaller babies who failed extubation. Comparison of the areas under the ROC curves (table 3) showed that low inspiratory pressures corrected for birth weight, except the mean MIP, were poorly predictive of extubation failure. Thus we would not recommend routine measurements of inspiratory pressure against an occlusion to facilitate the appropriate timing of extubation. In conclusion, extubation failure in very immature infants is more accurately predicted by low gestational age and older postnatal age than assessments of respiratory load or respiratory muscle strength.

\section{ACKNOWLEDGEMENTS}

GD was supported by a Children Nationwide Medical Research Fund/ Nestle Research Fellowship. AE was supported by the King's College Hospital/SLE Ltd Research Fellowship. The equipment for this study was provided by a grant from the Children Nationwide Medical Research Fund.

\section{Authors' affiliations}

G Dimitriou, A Greenough, A Endo, S Cherian, G F Rafferty,

Children Nationwide Regional Neonatal Intensive Care Unit and

Department of Respiratory Medicine, King's College Hospital, London, UK

\section{REFERENCES}

1 Thompson PJ, Greenough A, Hird MF, et al. Nosocomial bacterial infections in very low birthweight infants. Eur J Pediatr 1992;151:451-4. 
2 Finer NN, Moriartey RR, Boyd J, et al. Post extubation atelectasis: a retrospective review and a prospective controlled study. J Pediatr 1979;94:110-13.

3 Dimitriou G, Greenough A, Laubscher B. Lung volume measurements immediately after extubation and prediction of "extubation failure" in premature infants. Pediatr Pulmonol 1996:21:250-254.

4 Dimitriou G, Greenough A. Computer assisted analysis of the chest radiograph lung area and prediction of failure of extubation from mechanical ventilation in preterm neonates. Br J Radiol 2000;73:156-9.

5 Kavvadia V, Greenough A, Dimitriou G. Prediction of extubation failure in preterm neonates. Eur J Pediatr 2000;159:227-31.

6 Heaf DP, Turner H, Stocks J, et al. Comparison of the occlusion and inflation techniques for measuring total respiratory compliance in sick intubated infants. Pediatr Pulmonol 1987;3:78-82.

7 Kavvadia V, Greenough A, Dimitriou G. Early prediction of chronic oxygen dependency by lung function test results. Pediatr Pulmonol 2000;29:19-26.

8 Altman DG, Bland JM. Diagnostic tests. 3. Receiver operator characteristic plots. BM 1994;309:188.

9 Hanley JA, McNeil BJ. The meaning and use of the area under a receiver operating characteristic (ROC) curve. Radiology 1982;143:29-36.
10 Dimitriou G, Greenough A, Dyke H, et al. Maximal airway pressures during crying in healthy preterm and term infants. Early Hum Dev 2000;57:149-56

11 Anzueto A Peters J, Tobin M et al. Effects of prolonged controlled mechanical ventilation on diaphragmatic function in healthy adult baboons. Crit Care Med 1997;25:1 187-90.

12 Marini JJ, Smith TC, Lamb V. Estimation of inspiratory muscle strength in mechanically ventilated patients: the measurement of maximal inspiratory pressure. J Crit Care 1986;1:32-8.

13 Black LF, Hyatt RE. Maximal static respiratory pressures in generalized neuromuscular disease. Am Rev Respir Dis 1971;103:641-50.

14 Byrd RB, Hyatt RE. Maximal static respiratory pressures in chronic obstructive lung disease. Am Rev Respir Dis 1968;98:848-56.

15 Polkey MIC, Hamnegard CH, Hughes PD, et al. Influence of acute lung volume change on contractile properties of human diaphragm. J Appl Physiol 1998;85:1322-8.

16 Agostoni E, Mead J. Statics of the respiratory system. In: Fenn WO Rahn H, eds. Handbook of physiology. Washington DC: American Physiological Society, 1964:397-409.

17 Aubier $\mathbf{M}$. Effect of theophylline on diaphragmatic muscle function. Chest 1987;92:275-315.

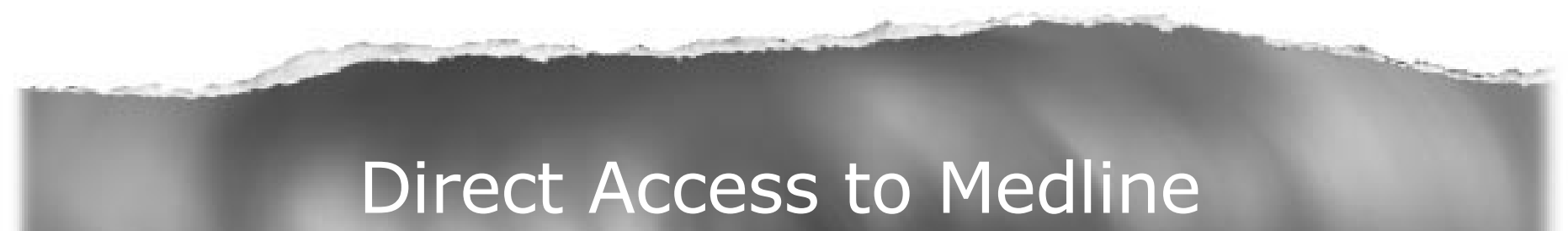

\section{Medline}

Link to Medline from the homepage and get straight into the National Library of Medicine's premier bibliographic database. Medline allows you to search across 9 million records of bibliographic citations and author abstracts from approximately 3,900 current biomedical journals.

\section{www.archdischild.com}

